Article

\title{
Studying Abroad from Home: An Exploration of International Graduate Students' Perceptions and Experiences of Emergency Remote Teaching
}

\author{
Yanning Dong ${ }^{1, *}$ and Aika Ishige ${ }^{2} \mathbb{C}$ \\ 1 Language Centre, Tsinghua University, Beijing 100084, China \\ 2 Center for Language Education, Ritsumeikan Asia Pacific University, 1-1 Jumonjibaru, Beppu, \\ Oita 874-8577, Japan; aishige@apu.ac.jp \\ * Correspondence: dongyn@mail.tsinghua.edu.cn
}

check for

updates

Citation: Dong, Y.; Ishige, A.

Studying Abroad from Home: An Exploration of International

Graduate Students' Perceptions and Experiences of Emergency Remote Teaching. Educ. Sci. 2022, 12, 98.

https://doi.org/10.3390/

educsci12020098

Academic Editor: Kelum

A.A. Gamage

Received: 31 December 2021

Accepted: 26 January 2022

Published: 31 January 2022

Publisher's Note: MDPI stays neutral with regard to jurisdictional claims in published maps and institutional affiliations.

Copyright: (C) 2022 by the authors. Licensee MDPI, Basel, Switzerland. This article is an open access article distributed under the terms and conditions of the Creative Commons Attribution (CC BY) license (https:// creativecommons.org/licenses/by/ $4.0 /)$.

\begin{abstract}
The temporary shift from face-to-face instruction to online teaching at North American universities as an alternative solution in response to the COVID-19 pandemic brought significant challenges to international students who had to study abroad from their home countries. Studies on how international students perceive their study-abroad-from-home experiences in such an emergency remote teaching (ERT) context remain scarce. Through the lens of community of inquiry and an additional perspective of emotional presence, this study explored 13 first-year international graduate students' perceptions and experiences of their learning in ERT. Based on the analyses of the prelearning questionnaire survey results and a series of three reflection journal entries, the study finds that teaching presence has played a vital role in shaping students' understanding and experiences when they participated in a study-abroad graduate program from their home countries. In addition, the participants demonstrated mixed emotions of both frustration and appreciation/thankfulness as well as an isolation-connectedness emotional trajectory during their learning process. The study inspires an exploration of more diverse options for international education programs and continued effort in providing institutional support to ensure better learning experiences in a post-COVID community of inquiry.
\end{abstract}

Keywords: study abroad; international education; community of inquiry; CoI; emergency remote teaching; ERT; online learning; COVID-19; graduate students

\section{Introduction}

As one of the top study-abroad destinations, Canada hosts a large population of international students every year. In 2020, international students represented $23.7 \%$ of the total enrolments in Canada [1]. Students who choose to study abroad usually aim at being immersed in the languages and cultures of the host countries while enjoying a quality education. However, the prevalence of COVID-19 in 2020 has made it very challenging for a large number of international students, particularly first-year international students, to come to Canada for their study-abroad programs. With international travels restricted, university campuses shut down, and classes moved online, they had no other choice but to study abroad from home by taking online courses.

Although online learning is not something new, it is worth noting that the courses that were temporarily shifted online in response to the COVID-19 crisis were situated within the emergency remote teaching (ERT) context, in which access to instruction is provided "in a manner that is quick to set up and is reliably available during an emergency or crisis" [2] (p. 7). They are different from the courses that are initially planned and designed to be taught online.

According to Khotimah [3], during the COVID-19 pandemic, 107 countries implemented national school closures on 18 March 2020. Higher education in many countries 
was forced to switch to ERT on that day or roughly around the same time. Since the outbreak of COVID-19, there has been a growing body of literature that explores students ERT experiences in many parts of the world such as Jordan [4], the US [5], Serbia [6], South Africa [7], Slovakia [8], the UK [9,10], and Hong Kong [11]. However, these studies focus on students in general with no special attention to international students. In addition, there has been little discussion about international students' ERT experiences in a Canadian context. This study intends to fill these gaps by exploring the experiences of first-year international students who were admitted to a Canadian university in the fall of 2020 and studied remotely from their home countries during the first semester into their graduate program. In light of the ongoing concern of COVID-19 and its long-term impact on future international education, it is crucial to obtain a better understanding of international students' learning experiences in the ERT context and to explore practical implications for optimizing international students' learning experiences in the post-COVID era.

\section{Theoretical Framework and Literature Review}

\subsection{Community of Inquiry}

This study draws on the community of inquiry (CoI) framework [12]. Since its initial publication in 2000, the CoI framework has been widely used, cited, and developed and has become one of the most extensively used frameworks in the research and practice of online learning [13-16]. The CoI framework provides a comprehensive model that includes three elements: cognitive presence, social presence and teaching presence [12].

In this model, cognitive presence involves four phases of practical inquiry (the exploration, construction, resolution, and confirmation of understanding) and is considered as being vital for critical thinking and academic success [12]. While cognitive presence is used to describe the process of practical inquiry, social presence refers to the creation of a climate that supports and encourages such intellectual inquiries. It includes three broad categories: emotional expression, open communication, and group cohesion [12]. Emotional expression refers to the ability to express feelings that are associated with educational experience and is often conveyed through the use of symbolic representations in an online learning context, such as emoticons, as well as the expression of humor and self-disclosure. Reflecting trust and acceptance, open communication encourages constructive responses to community members by asking questions, expressing agreement, quoting other's messages, expressing appreciation, and so forth. The third category, group cohesion, refers to a sense of belonging and community building. The third element of the CoI model, teaching presence, involves instructional design and organization, facilitating discourse and direct instruction $[17,18]$. In light of the purpose of achieving meaningful online learning experiences, teaching presence plays a vital role in integrating and supporting the cognitive and social processes [17]. Instead of using teacher presence, as Garrison [17] explained, teaching presence allows every member of the community to make a contribution to achieving self-directed and self-disciplined learning outcome.

The CoI model provides a comprehensive guide for the understanding and research of online learning experiences [12]. During the past two decades, the CoI framework has been extensively applied and examined [19-23], both qualitatively and quantitatively, resulting in a critical understanding of the relationships among the three presences and how they are connected to other elements. Some researchers suggest considering other possible presences, such as learning presence [24], autonomy presence [25], and emotional presence [26-28]. Although these presences are closely related to the elements in the original CoI framework, there seems to be an increasing interest in exploring the possibility of viewing them as an additional component of the framework.

\subsection{Emotional Presence}

Among these additional components, emotional presence has been receiving more attention particularly due to recent discussions on the relationship between emotion and online learning [29-31]. As Tores and Evans [30] stress, emotion plays a significant role 
in preventing an isolated online learning experience and is as important as the curriculum itself. However, it has not been extensively examined or considered in research and practice $[26,30]$. In the CoI framework, "emotional expression" is referred to as both conventional and unconventional expressions of emotion (such as punctuation, capitalization, and emoticons) and is placed as a sub-component of social presence [17]. ClevelandInnes and Campbell's [26] findings indicate that emotion is present in online learning communities and plays a role in all three presences of the CoI framework. Based on their findings, Cleveland-Innes and Campbell [26] (p. 283) provide the following definition for emotional presence:

Emotional presence is the outward expression of emotion, affect, and feeling by individuals and among individuals in a community of inquiry, as they relate to and interact with the learning technology, course content, students, and the instructor.

Cleveland-Innes and Campbell's [26] proposal has inspired further explorations of emotional presence as an additional component of the CoI model. For example, Majeski et al.'s [28] study investigated the relationship between emotional presence and teaching presence. With an understanding of emotional presence as emotional perception, understanding, regulation, and facilitation, they conceptualized emotional presence as part of teaching presence that affects learner emotional presence, social presence, and cognitive presence. Using Cleveland-Innes and Campbell's [26] emotional constructs, a recent study by Jiang and Koo [27] examined the emotional presence and relationship building in a group of non-traditional graduate students' online learning and identified mixed emotions and a desperate need for emotional support. While the CoI model $[12,17]$ provides a holistic model to guide the design and conduction of the present study, the additional element of emotional presence is carefully considered in the analysis of the research findings with particular concerns regarding the impact of COVID-19 on students' emotions in online learning.

\subsection{Online Learning and Emergency Remote Teaching (ERT)}

The current teaching system, condition, and context that emerged from the COVID-19 pandemic have been conceptualized with multiple terms, such as online learning and distance education [5]. However, these concepts are inaccurate as they have developed to embody different learning and teaching environments $[2,32,33]$. To be more specific, distance education theories were developed when "resources, platforms and teaching methods were carefully considered and took time to develop and curate" [34] (p. 61). To distinguish from these contexts, Hodges et al. [2] have proposed "emergent remote teaching $($ ERT)" as an alternative term to describe the current classroom system introduced under the COVID-19 pandemic. According to them, ERT is a "forced" transition to online teaching or learning due to the crisis that was initially planned to be offered face-to-face, blended, or in a hybrid form [2]. Bozkurt and Sharma [33] iterate this point as follows: "while distance education has always been an alternative and flexible option for learners, emergency remote teaching is an obligation" (p. II, emphasis original).

Due to its crisis-responsive nature, ERT is "a temporary solution" that is implemented only during a crisis or disaster and is supposed to be abated afterward [2,33]. In this emergency, the focus is on how institutions can make this massive, drastic transformation of their education system, rather than whether implemented online teaching methods can guarantee quality education [35]. This certainly depends on each institution, and for the successful transformation, it is imperative for institutions to secure "[r]eliability and sufficient availability of Information Communication Technology [ICT] infrastructure, learning tools, digital learning resources in the form of Massive Open Online Courses, e-books, e-notes" [35] (p. 18). Available technological resources significantly affect pedagogical possibilities at the classroom level. In addition, students and instructors have to deal with the forced transition to online teaching, regardless of their previous online teaching/learning experience, digital competence, and level of comfort with that environment. 
Although the present study is conceptualized as ERT, it also requires attention that the ongoing almost-two-year-long ERT situation under the COVID-19 pandemic has consequently created so-called "new-normals". In the context of higher education, the pandemic promoted the implementation of online learning systems and the training of instructors to teach online. In other words, studies conducted during this pandemic could present practical implications for future online learning systems and models [8].

\subsection{ERT during the COVID-19 Pandemic}

As of today, ERT studies have been conducted largely in two areas: effective teaching approaches and students' learning experiences. Garrison et al. [12] claimed that students' overall learning experiences and community building depend on instructors' effective presence and leadership, particularly in an online classroom context. Likewise, during the COVID-19 pandemic, studies have found the multiple, important roles that instructors took in their ERT classrooms $[5,7,10,11,36,37]$. For example, through their survey research on undergraduate students in Hong Kong, Tsang et al. [11] concluded that course design was a key predictor of perceived learning experiences and effectiveness. In Gelles et al.'s [5] case study of engineering undergraduate students in the US, instructors' facilitation and mentorship were particularly appreciated by students, pointing to the need for shifting the focus from making courses rigorous to being compassionate to students during ERT. Studies, such as those of Doll et al. [36] and Kifle Mekonen and Chiamaka Nneoma [37], found that teachers also had to play a tech-support role in the ERT context to troubleshoot unexpected technical issues that students faced.

The precarious roles that instructors had to take amid the pandemic were a reflection of students' diverse expectations and demands during the crisis. Studies on students' ERT experiences have been conducted in many parts of the world [4-11]. These findings overall suggest how various factors-both in- and inter-dependently-shaped students' learning. One of the most explored are factors that smoothened students' ERT experiences. In Kovačević et al.'s [6] survey research on university students in Serbia, previous online learning experience and familiarity with learning platforms were the predictors of students' learning satisfaction. On the contrary, Poláková and Klímová [8] found in their survey that participating students in Slovakia did not consider lack of experience with online learning hindered their learning. The researchers concluded that this inexperience was compensated by students' existing digital competence.

The previous studies have also shed light on the importance of paying attention to localized and personalized situations in the ERT context. For example, in Makgahlela et al.'s [7] study on a rural university in South Africa, the students' narrative vividly conveyed the contextual reality where they struggled with multiple issues such as the lack of sufficient devices, data, and a safe, quiet space to study, calling for their university to reopen because their online learning was not functioning at all. From a different context, in aforementioned Gelles et al.'s [5] case study on American university undergraduates, gendered responses in their ERT experience were prominent: Female students tended to have more housework and family duties, whereas males tended to feel there was more free time during the pandemic. Issues surrounding digital equity were prominent in Greenhow et al.'s [38] review of newspaper articles in the US and the UK, revealing how technology access and social support played a role in widening the gaps between students from low- and high-income families in these two countries.

The previous literature, in sum, points to the fact that students' ERT experiences have been shaped through numerous factors, including the availability of support from the institution and/or instructors and students' assets-from financial, sociocultural, to technological ones. This means that faculties and institutions must reflect on the assumptions that they make about their students and pay attention to students' personal lives for a successful ERT experience [5]. This is a challenge for almost any school and educator, but especially for the ones that accommodate international students. Especially notable are the experiences of first-year international students, most of whom had to stay in their home 
countries due to border restrictions during the year 2020. Unfamiliar with new education systems and physically apart from the academic communities, these students started their "study-abroad-from-home" journey alone. International students' ERT experiences and, in particular, first-year international graduate students' ERT experiences have received scant attention in the existing literature. To fill this gap, the present study focuses on this specific group of students with an aim to explore the following questions:

1. What are international graduate students' perceptions of online learning and study abroad in an ERT context?

2. What are international graduate students' ERT experiences when studying abroad from home?

\section{Methods}

\subsection{Research Site}

This study took place in a large public research university located on the West Coast of Canada. According to the official website of the university, more than one-fourth of the enrolled students were international students in the year 2020. The university's Faculty of Education offers graduate programs in various disciplinary areas such as language and literacy education, curriculum and pedagogy, educational studies, and educational counselling and special education, and so forth.

\subsection{Participants}

The study recruited 15 international graduate students from the university's Faculty of Education, among whom two withdrew during the data collection. A combination of snowball and convenience sampling was used to recruit the participants who: (1) started their graduate program at the university in September 2020, (2) resided outside of Canada in 2020 Winter Term 1 (September-December, 2020), and (3) took one or more courses in 2020 Winter Term 1.

International graduate students who participated in this study were enrolled in the following degree programs: Doctor of Philosophy (PhD, $n=1)$, Master of Arts (MA, $n=2)$, and Master of Education (MEd, $n=10)$. Ten of the participants were in their 20s, and three of them were in their 30s. Eleven students identified themselves as female, whereas two did as male. All the participants were studying in their home countries during 2020 Winter Term 1. The participants were taking one to three courses during the term, and the course formats included synchronous, asynchronous, and hybrid courses. Detailed demographic information of the participants is listed in Table 1.

Table 1. The demographic information of the participants.

\begin{tabular}{|c|c|c|c|c|c|c|}
\hline Participant & $\begin{array}{l}\text { Where They } \\
\text { Were during } \\
\text { Term } 12020\end{array}$ & Degree & Program & Gender & $\begin{array}{c}\text { Number of } \\
\text { Courses Taken }\end{array}$ & Course Formats \\
\hline P1 & China & MEd & Language education & $\mathrm{F}$ & 3 & $\begin{array}{l}\text { Synchronous (1) } \\
\text { Asynchronous (2) }\end{array}$ \\
\hline P2 & China & MEd & $\begin{array}{l}\text { Educational counseling and } \\
\text { special education }\end{array}$ & $\mathrm{F}$ & 3 & $\begin{array}{l}\text { Synchronous (2) } \\
\text { Asynchronous (1) }\end{array}$ \\
\hline P3 & China & MA & Language education & M & 3 & $\begin{array}{l}\text { Synchronous (2) } \\
\text { Asynchronous (1) }\end{array}$ \\
\hline P4 & East Asia * & MEd & Language education & $\mathrm{F}$ & 2 & $\begin{array}{l}\text { Synchronous (1) } \\
\text { Asynchronous (1) }\end{array}$ \\
\hline P5 & China & MEd & Language education & $\mathrm{F}$ & 2 & $\begin{array}{l}\text { Synchronous (1) } \\
\text { Asynchronous (1) }\end{array}$ \\
\hline P6 & China & MEd & $\begin{array}{l}\text { Educational counseling and } \\
\text { special education }\end{array}$ & $\mathrm{F}$ & 2 & $\begin{array}{l}\text { Synchronous (1) } \\
\text { Asynchronous (1) }\end{array}$ \\
\hline P7 & Japan & MEd & Curriculum and pedagogy & F & 2 & Synchronous (2) \\
\hline P8 & Nigeria & MEd & Curriculum and pedagogy & M & 1 & Synchronous (1) \\
\hline
\end{tabular}


Table 1. Cont.

\begin{tabular}{|c|c|c|c|c|c|c|}
\hline Participant & $\begin{array}{l}\text { Where They } \\
\text { Were during } \\
\text { Term } 12020\end{array}$ & Degree & Program & Gender & $\begin{array}{l}\text { Number of } \\
\text { Courses Taken }\end{array}$ & Course Formats \\
\hline P9 & Russia & MA & $\begin{array}{l}\text { Educational counseling and } \\
\text { special education }\end{array}$ & $\mathrm{F}$ & 3 & Synchronous (3) \\
\hline P10 & East Asia * & $\mathrm{PhD}$ & $\mathrm{n} / \mathrm{a}$ & $\mathrm{F}$ & 2 & $\begin{array}{l}\text { Synchronous (1) } \\
\text { Hybrid (1) }\end{array}$ \\
\hline P11 & Nigeria & MEd & Curriculum and pedagogy & $\mathrm{F}$ & 2 & $\mathrm{n} / \mathrm{a}$ \\
\hline P12 & East Asia * & MEd & $\begin{array}{c}\text { Educational counselling and } \\
\text { special education }\end{array}$ & $\mathrm{F}$ & 3 & $\begin{array}{l}\text { Synchronous (1) } \\
\text { Asynchronous (2) }\end{array}$ \\
\hline P13 & Cambodia & MEd & Education studies & $\mathrm{F}$ & 2 & $\begin{array}{l}\text { Synchronous (1) } \\
\text { Hybrid (1) }\end{array}$ \\
\hline
\end{tabular}

* P4, P10, and P12 indicated their preference for not disclosing their specific location and nationality.

\subsection{Data Collection and Analysis}

Employing a mixed-method approach, the present study consisted of two phases of data collection: (1) pre-learning questionnaire survey before the semester started, and (2) three reflection journal entries during the semester. In the first phase of data collection, the participants were invited to respond to the pre-learning survey questionnaire, which was designed to elicit information regarding their personal background information (e.g., nationality and age), experiences and perceptions of online learning, pre-learning activities, and understanding of "study abroad" and "study abroad from home". The questions were asked in various formats such as multiple choice, Likert scale, and open-ended questions. In the second phase of data collection, the participants wrote three short (around 200 to 300 words) reflection journal entries where they reflected on their experiences of learning in their registered courses at the beginning, middle, and end of their first semester in their graduate program. Some prompts were provided to help develop ideas, but the participants were encouraged to write anything that stood out to them (refer to the Appendix A for details). This unique approach of using multiple reflection journal entries throughout the semester is different from the ones used in the previous studies. It enabled us not only to explore what the students experienced in this specific learning context but also to trace how their understandings and emotions develop as their learning progressed. This approach is beneficial for capturing the complexities of the issues being explored in this study.

Garrison's [17] CoI coding template was used when analyzing the three presences (cognitive, social, and teaching presences). Although emotional expression is only one of the categories in social presence in the original CoI framework [12], it is worth being viewed as a unique presence in addition to the three presences since emotional expression emerged as an exceptionally recurrent theme in the journal data. To capture this emerging theme in depth, we coded emotional presence by drawing on the 23 emotional constructs proposed by Cleveland-Innes and Campbell [26]. Since loneliness and isolation have become highly concerning due to the impact of such measures as emergent lockdowns and social distancing during the pandemic [39], we considered it necessary to pay special attention to this emotion when analyzing the participants' emotional presence. In opposition to being isolated, the feeling of being connected might also be looked at in this context.

The two authors first coded 15\% of the journal data (i.e., two participants' sets of journals) independently and reviewed their code consistency. The inter-rater reliability rate was high (86\%). Inconsistent codes were identified, discussed, clarified, and adjusted. Then, the second author coded the rest of the journal data, which was reviewed by the first author.

\section{Results and Discussion}

To obtain a comprehensive understanding of first-year international graduate students' perceptions and experiences of online learning and study abroad in an ERT context, we 
analyzed the participants' pre-learning survey results and the three reflection journal entries that they completed at the beginning, middle, and end of the semester.

\subsection{Perceptions of Online Learning and Study Abroad in an ERT Context}

According to the results of the pre-learning survey, more than $60 \%$ of the participants had never taken any online courses before. About $80 \%$ of those who had previous online learning experiences took asynchronous courses, but none of them showed strong satisfaction towards those learning experiences. Although they liked the flexibility of learning schedules and locations as well as easy access to learning content, they were not satisfied with the communication with teachers and peers in online learning.

The participants were invited to explain why they applied for the graduate program at the participating university. Since all the participants were enrolled in at least one course in the semester when the study was conducted, they were also required to explain why they did not defer their admission when they knew they had to take all the courses online without being able to come to campus. The reasons for their program application were mainly related to the ranking of the university and the expectation for studying abroad in Canada. Time and scheduling concerns were the major considerations for their reluctance to defer admission. Although the courses were temporally shifted online, they held the expectation for completing the program within the initially planned time frame. As one participant wrote in their open-ended response, "online or not, I will learn".

In the pre-learning survey, the participants were also invited to describe their understanding of study abroad and study abroad from home. While a new environment, people, and cultures appeared to be the defining characteristics in the participants' understanding of study abroad, many described their expectation for an immersive experience of studying and living in another country, which was in great contrast to their understanding of studying abroad from home. The latter appeared to be much less attractive as evident in such descriptions: spending "way more time in front of screens", "lost the chance of going to new places", "an isolating experience", "there is nothing meaningful to study abroad from home", and so forth. Although some participants tried to be more optimistic and mentioned the advantage of saving living expenses, it was apparently not something they cared about most. One participant even described a study-abroad-from-home program as a "cheap program" featuring "low bars for entry". According to the participants' understanding, having to attend a study-abroad program from one's home country lacks the most important elements that attract learners to study abroad and is associated with a negative vision of an isolated learning experience-isolated from the place, people, and cultures that learners could have explored and experienced otherwise.

In addition to these questions in the pre-learning survey, the participants were also asked to provide a metaphor to describe their overall study-abroad-from-home experiences in their third reflection, which was collected at the end of the semester. Surprisingly, the metaphors were not associated with an entirely negative image. In fact, some of these metaphors showed a sense of positiveness with the use of such terms as "adventure", "life-changing", or "comfortable". Some of the metaphors conveyed a sense of unreality and loneliness through the use of such terms as "dream", "an artificial wave pool", and "a race with myself". Although none of the participants depicted it as a negative experience, their expectations for a study-abroad program did not seem to have been fully fulfilled. As one participant wrote, "Studying abroad from home is like having a meal blended together and drank, you get all the relevant nutrients but the process of 'eating' is less enjoyable". It is worth digging deeper into their detailed reflection notes to explore what they had experienced that led to these understandings and emotions.

\subsection{ERT Experiences}

Both the pre-learning survey results and the three reflection journal entries were analyzed to explore the participants' ERT experiences. The CoI model [12,17] was employed as a framework to guide the understanding of students' reports and reflections. In addition, 
25 emotional constructs adapted from Cleveland-Innes and Campbell [26] were used to analyze the participants' emotional presence and change of emotions throughout the whole semester.

\subsubsection{Cognitive Presence}

Cognitive presence relates closely to students' learning process in terms of how they recognize problems, explore relevant issues through critical reflections and discourse, construct meaning, and apply what they learn [12]. However, when the participants reflected on their learning, instead of commenting on the practical inquiry, most of them focused on the challenges brought by the format of learning during ERT. Challenges such as technical issues, time differences, and the mental pressures due to the format of online learning strongly affected students' cognitive presence. As a participant from Russia, P9, described in her first reflection, "It's harder with the studies all being in my laptop: usually they contained from several activities, like checking class notes, reading book, watching additional videos. Now it's all there, so I get tired much faster". Several participants complained about the challenges brought by ineffective time management and huge time differences. The participant mentioned that she had to take live learning sessions when her partner was sleeping, so she had to study "in a small kitchen, with a little light and no noise". Several other participants, too, experienced such frustrations as having to take courses at 12 a.m., 3 a.m., or 6 a.m. The narrative reflection of a participant from Nigeria, P8, clearly illustrates the challenges for cognitive presence in such an ERT context:

It is Wednesday, almost 12 am WAT, my eyes are heavy but I have to purchase a large sum of data internet subscription that will be more than enough for the next $3 \mathrm{~h}$, hoping for a stable bandwidth without interruption as class is in session, my torchlight by my side just in case of a power outage.... The timing for classes is still of a huge disadvantage to me, having classes once a week doesn't look bad except that you have $8 \mathrm{~h}$ difference between both countries involved. I am a teacher and I currently go to work every day, my classes are usually 12am WAT so I have to either stay awake till then or set my alarm, so I have lectures 12 $\mathrm{am}-3 \mathrm{am}, 2 \mathrm{~h}$ sleeping time and then I am up in preparation for work. If classes were held in-person, I will be restricted to four working hours if I have to work and I will have much time for studies but you don't find such employers here that understands your situation and the need for a lesser working hours. Also, I am not satisfied with my productivity level, no after class discussions with my amazing course mates which can yield good fruits.

To reduce internet consumption, the participant also reported having to use a mobile phone instead of a laptop for the online courses, which prevented him from performing "proper class participation in class activities". A participant from Cambodia, P13's learning was also affected by such financial challenges. She noted that,

I have been considering that taking a break from my job would provide me the time I need, but the tuition isn't going to pay itself and so isn't the insurance fee I am being charged for though I am not physically there.

Besides the impact of financial issues, students' learning was also negatively affected by the social environment of their home countries. Because of the high tensions and unrest in his home country, P8 noted that "I feared for my life during the day as I step out and I try to remain calm in every class putting aside the squabbles of the day".

These notes reflect great concerns about the several hindering elements that have been recently investigated [7,40-42]. All these factors, time differences, access to the Internet, and financial and security issues have made educational equity a big concern in this specific learning context. As Ezra et al. [40] advocated, relevant mitigating strategies should be considered to identify and address educational equity issues in order to meet the needs of vulnerable populations. 
Teaching presence, particularly, the instructor's discourse facilitation in online discussions, had a great impact on students' cognitive presence. A lack of instructor feedback may negatively affect students' inquiry process. As a participant from East Asia, P4, reflected in her second reflection, she felt frustrated with online discussions not because of the task of writing discussion posts but because of the uncertainties and self-deprecation she felt when the instructor did not respond to her posts. She noted that,

Posting itself is not very difficult for me now, but I would like some comments from professors on my posting to know whether I was on the right track. Even when I read the required readings and receive replies from my classmates, I still don't know if my reflections hit the nail on the head. When I receive no comments from professors, I always feel like my reflections are meaningless and deserve low marks. It's discouraging and makes me nervous.

Although, as the participant clearly understood, it might be impossible for the instructor to respond to every student, facilitation of discourse is particularly important in such an ERT context where personal one-on-one communications are largely limited.

\subsubsection{Social Presence}

Pertaining to the ability of "projecting themselves socially and emotionally, as 'real people"' [12] (p. 94), social presence involves every member of a community of inquiry and faces great challenges in building the connectedness in an ERT context. According to the CoI framework, social presence consists of three indicators: emotional expression, open communication, and group cohesion [12]. Evidence related to emotional expression is presented and analyzed in detail in the section of emotional presence.

The process of how the participants built the online community, just as Brown [43] identified, went through three stages, from online interactions to thoughtful exchange of ideas and finally to achieving a feeling of camaraderie. The participants' reflections show that open communication and group cohesion played equally important roles in this process and were both affected by course formats (synchronous vs. asynchronous), participants' backgrounds, and teaching presence. The participants seemed to find it easier to start the community-building process with the synchronous courses where they "feel connected" (e.g., P4) with the instructors and classmates. They also found it easier to connect with the classmates who share the same cultures or nationalities (e.g., P5). Interestingly, as a participant from China, P5, explained, she felt closer to other students who were also in China majorly because they could have more interactions through a shared SNS toolWeChat. In fact, the use of WeChat also helped extend their communication from academic discussions to personal ones because of the access to personal WeChat postings. While these participants seemed to have no difficulty interacting with classmates from the same country, they came across big challenges getting to "know" more about classmates from other countries. Some students (e.g., P6, P9) noted their expectations for learning more about their classmates but made little progress throughout the whole semester due to not having enough opportunities for more in-depth personal interactions.

Teaching presence, specifically, instructional design and discourse facilitation, contributed to stronger group cohesion, which is particularly important for community construction in an e-learning context [17]. The feeling of connectedness became stronger as more group interactions occurred for the purpose of completing group discussions or group assignments. As a participant from East Asia, P12, noted, her instructors encouraged peer feedback, which led to an active exchange of ideas in the online discussion forum. This not only helped her think more critically about the course content but also gave her the chance to work more closely with a classmate who greatly supported her studies. The increasingly stronger group cohesion, as mentioned in P4's final reflection, made her feel as if she were together with her classmates in the classroom (rather than in a virtual classroom).

In this ERT context where students had to (rather than chose to) study online, they had stronger expectations for community building and put greater effort into learning more about each other. For example, although P13 was very sleepy when attending synchronous 
sessions because of the time difference, she managed to join earlier every time in order to chitchat with her classmates or even just to listen to them. The sense of "real" connections with instructors and classmates seemed to be especially important and valuable in an isolated and physically distanced environment brought by the pandemic.

\subsubsection{Teaching Presence}

Teaching presence is conceptualized as having three components: instructional design and organization, facilitating discourse, and direct instruction [17]. A lot of the participants' survey responses and reflection notes that were related to teaching presence connected to the component of instructional design and organization. They commented on both the instructional support before and during the course delivery and the instructional design of the online courses. As found in the survey results, all the participants had received the course syllabi and emails from the instructors before the courses started. Almost all (12 out of 13) of them received access to the online learning platform prior to the start of their courses. The pre-learning information and support were perceived to be very helpful. As a participant from Japan, P7, commented, the course syllabi she received before the courses were very "informative and helpful", which made her "feel a lot secured". In fact, this pre-learning instructional support may strongly affect students' initial experience when they embarked on their ERT journey. One participant from China, P1, experienced significant challenges when downloading the reading materials due to internet restrictions until one of the instructors helped her with the issue. Being a tech-support, as noted in previous research (e.g., [36,37]), becomes an important role that instructors are expected to take on in ERT. The participants also found it helpful when the instructors were clear about their expectations, open to questions, and willing to make adjustments. For instance, three participants (P2, P4, P6) mentioned that their instructors offered an extension for the submission of their final papers, which was "so helpful" and "really great".

The participants appreciated not only their instructors' support but also how they designed the courses, both synchronous and asynchronous ones, to accommodate the needs of all the students in the ERT context. Although most of the participants provided very positive comments on the course design and appreciated the instructors' effort in designing and organizing the courses, particularly in terms of their clarity, they showed clear preferences towards some course designs that worked more effectively in easing the pressure of learning and encouraging group interactions. Higher student satisfaction was shown when the course designs matched students' learning styles. These findings are consistent with those of Tsang et al. [11], who emphasized students' appreciation towards instructors' facilitation and course design in an ERT context.

It is worth noting that the university where the study was conducted offered a series of workshops before the 2020 fall term, which offered topics relevant to online course design strategies and principles, examples and templates, technologies and tools, and one-on-one consultations. Such institutional support might have played a very important role in achieving student satisfaction with the course designs. At the same time, as VanLeeuwen et al. [44] indicate, there is an emergent need for professional development in digital education and this need has become "pressing" due to the impact of the pandemic.

As Garrison [17] clarifies, both teachers and learners contribute to teaching presence. Some participants noted down how they exerted great effort into monitoring and managing their own learning in order to achieve better learning efficiency and outcome. P3 noted that online learning made him "think ahead" and "make plans". They also showed initiative in facilitating discourse by actively exchanging ideas and giving and receiving feedback in their online discussion forums, which positively affected the cognitive and social presences in their learning community.

\subsubsection{Emotional Presence}

Emotional expression is housed under the dimension of social presence in the original CoI framework. However, it is proposed that emotion should be addressed as a unique 
presence independent from social presence (e.g., [27]). Because of the uniqueness of the ERT context in which the study was conducted and its potential impact on learners' emotions, we considered it reasonable to pay special attention to emotional presence and how it relates to the other three presences of the CoI framework. Before the start of their study-abroad-fromhome program, most of the participants self-identified their emotions as being uncertain $(62 \%)$, with a small number of participants identifying themselves as being excited $(38 \%)$ or concerned (38\%). These complex feelings were also identified in their reflection notes. Using the 25 emotional constructs adapted from Cleveland-Innes and Campbell [26] (see Table 2), we identified 20 emotions, with appreciation being the most recognized (83 times) emotion, followed by frustration (75 times) and thankfulness (62 times). Surprisingly, a closer look at loneliness/isolation and connectedness, the two additional emotions we added to Cleveland-Innes and Campbell's list of emotional constructs, finds that connectedness was recognized more times (17 times) than loneliness/isolation (11 times). Table 2 shows the times of recognition for each emotion and the example quotes:

Table 2. Emotional presence identified in the reflection journals.

\begin{tabular}{ccl}
\hline Emotional Construct & Times of Recognition & \multicolumn{1}{c}{ Example Quotes } \\
\hline Appreciation & 83 & I am very appreciative of ... \\
Delight & 5 & I am glad ... \\
Desire & 4 & I would love to ... \\
Disappointment & 19 & I wish we could ... \\
Dislike & 0 & \\
Emphatics & 20 & $\ldots$ is muccccch harder. \\
Enjoyment & 6 & I enjoy ... \\
Excitement & 8 & I was excited ... \\
Fear & 24 & $\ldots$ can be a real nightmare \\
Frustration & 75 & I'm struggling with ... \\
Happiness & 6 & I feel happy that ... \\
Hope & 18 & I hoped that I can ... \\
Humor & 0 & \\
Irony/sarcasm & 0 & \\
Like & 11 & I like ... \\
Passion & 0 & \\
Preference & 13 & I prefer to ... \\
Pride & 2 & I am proud to ... \\
Surprise & 4 & To my surprise ... \\
Thankfulness & 62 & I am thankful for that ... \\
Unhappiness & 1 & I am not satisfied with ... \\
Wonder & 2 & $\ldots$ feels surreal. \\
Yearning & 0 & $\ldots$ is my dream \\
Loneliness /Isolation & 11 & I feel more connected ... \\
Connectedness & 17 &
\end{tabular}

It is probably not surprising at all to find frustration to be one of the most recognized emotions, considering the unique situation in which a study-abroad program was pursued remotely from students' home countries. The frustrations were majorly caused by technological issues, heavy workload, time differences, time management, limited communication channels, and so forth. However, it is somehow unexpected to find more recognitions of positive emotions of appreciation and thankfulness. Additionally, these two emotions were often expressed simultaneously. For example, P3 expressed his feeling of appreciation and thankfulness when reflecting on the support received from an instructor before the course started:

A fascinating thing is one of my course instructors contacted us in advance (by sending us a long email) and told us about the required textbook and learning materials for the class. I appreciate such responsible teachers. 
The emotion of loneliness/isolation emerged 11 times. Some participants felt that they were not connected to their classmates or with the community, although they could communicate with their teachers and classmates online. In P3's words, "It seems that we are separated by something". Unexpectedly, the emotion of connectedness emerged more times than loneliness/isolation. A comparison of the coding of each participants' three reflection journal entries finds that loneliness/isolation was mostly spotted in the participants' first reflection, yet connectedness was majorly spotted in the second or third reflections. As evident from the participants' notes, social and teaching presences' positive impact on community building began to influence participants' feeling of connectedness to the community as the courses progressed. P2 noted that,

After corresponding frequently through emails and several chances to have direct conversations (one-on-one Zoom meeting/Zoom meeting for small groups), I do feel more connected to my teachers, and I sense that my teachers might know me better in terms of my interests and areas of expertise.

$\mathrm{P} 4$ also noted the feeling of connectedness in her second reflection:

After a couple of months, I feel more connected with my classmates and my professors. Group assignments that I had in my courses gave me opportunities to talk and interact with my classmates. These opportunities are valuable to get to know them. I also met my professors online, and I felt stronger connections with them than before.

In addition, some participants' agentive effort in actively seeking opportunities for both academic and personal interactions (e.g., exchanging thoughtful ideas and liking classmates' SNS posts) led to a stronger sense of belonging to the community.

In line with Jiang and Koo [27], the study finds mixed emotions among the participants, among which frustration was one of the most recognized emotions. Nevertheless, different features of emotional presence were identified. For example, instead of demonstrating a strong emotion of happiness or enjoyment, participants in this study showed a greater sense of appreciation and thankfulness towards the situation and every community members', particularly the instructors', effort and contribution. They understood the challenges that everyone was facing in this ERT context and thus appreciated the support they could receive to help them overcome the frustrations. In addition, as the participants in this study were invited to note down their reflections three times during the semester, it is possible to identify the change of emotions in this process (such as the spot of isolation and connectedness). Tracing these emotional changes allows us to obtain a better understanding of the interrelated impacts of cognitive, social, and teaching presences on participants' emotional presence.

\section{Conclusions}

The present study was designed to explore first-year international graduate students' perceptions and experiences of a study-abroad-from-home program in an ERT context. By investigating the results of a pre-learning survey and participants' self-reflections collected throughout the first semester of their program, the study finds that students were aware of the advantages and challenges of online learning. The participants in the study were determined to complete their graduate program even though they had to take online courses without physically being in Canada, but they had a clear understanding of the differences between study abroad and study abroad from home before the program started. Although a few participants changed their views after the completion of their first semester (e.g., one participant considered it as a "life-changing" experience), most of the participants viewed it as something unreal due to a physical disconnectedness from the place, people and cultures of the host country.

Through the lens of the CoI framework [12,17], we analyzed the survey results and reflection notes in order to obtain an understanding of students' learning experiences from the aspects of three presences (cognitive, social, and teaching presences) and an additional 
aspect of emotional presence. Supporting and extending the previous understanding of the importance of teaching presence [39], the study finds that teaching presence played a vital role in shaping students' ERT experiences and had a positive impact on cognitive, social, and emotional presences. Some participants highly appreciated the significant role of teachers in defining their online learning experiences. This finding confirms the pressing need for institutional support and professional development programs in digital education. It is also worth noting that the impact of teachers' role, as students perceived, was actually implemented through teaching presence that involves the contribution of both teachers and learners in the community of inquiry [17]. It is important not to ignore the positive impact of learner agency in shaping their own ERT experiences.

The investigation of students' emotional presence finds complex emotions of both positive and negative ones. While students experienced a lot of frustrations, which is very understandable considering the unique learning and social contexts, they also showed strong emotions of appreciation and thankfulness, showing their empathetic understanding of the situation in which every community member was trying their best to adapt to the "new normal". In addition, although many participants experienced emotional isolation at the beginning of the ERT journey, there emerged an increasing sense of connectedness as the journey progressed. This emotional trajectory confirms the positive effects of teaching and social presences, and at the same time, reveals the effectiveness of students' agentive effort in actively building up community and connecting with each other in such an isolated learning context.

Since the participants of the study were limited to graduate students who majored in education, the findings may not be directly generalizable to other disciplinary areas. For example, students who took lab courses might have experienced other types of challenges that were not identified in this study. A cross-disciplinary investigation on similar topics would be helpful for providing more insights into the issues discussed in the study. Similarly, while our study relied on convenience sampling and involved a small number of participants, a larger scale of this study with different sampling methods (e.g., random-quota sampling) will enhance the validity of the utilized frameworks. Additionally, since emotional presence can be a good indicator of students' ERT experiences, more empirical studies that focus on emotional presence are necessary to explore a better understanding of students' emotional trajectories in various remote learning contexts and the interrelationship between emotional presences and the other three presences.

The prevalence of the COVID-19 pandemic has brought ongoing concerns to the planning and implementation of international education. Although international students would accept study-abroad-from-home programs as an, or actually the only, option in an ERT context, it is different from their vision of and expectation for study-abroad programs. Considering the importance of international education, the importance of the international student population to Canada and many other countries, as well as the long-term impact of COVID-19 on international education, an exploration of more diverse options for international education programs in and out of crisis circumstances would be necessary. The newly gained insights into international graduate students' perceptions and experiences in ERT also imply the necessity of continued institutional support to ensure better learning experiences in a post-COVID community of inquiry.

Author Contributions: Conceptualization, Y.D. and A.I.; methodology, Y.D. and A.I.; validation, Y.D. and A.I.; data curation, Y.D. and A.I.; writing — original draft preparation, Y.D. and A.I.; writingreview and editing, Y.D. and A.I.; supervision, Y.D.; project administration, Y.D.; funding acquisition, Y.D. All authors have read and agreed to the published version of the manuscript.

Funding: This study was part of a research project funded by LLED Seed Funding, University of British Columbia.

Institutional Review Board Statement: The study was conducted in accordance with the Declaration of Helsinki, and approved by the Behavioural Research Ethics Board of the University of British Columbia (protocol code: H20-02640 and date of approval: 11 September 2020). 
Informed Consent Statement: Informed consent was obtained from all subjects involved in the study.

Data Availability Statement: Not applicable.

Acknowledgments: We appreciate the Department of Language and Literacy Education (LLED), UBC, for supporting the research project and granting the funding to Ling Shi and Yanning Dong. We are thankful for the students who participated in the study and the students who circulated our project information to potential participants. We also thank the reviewers for their constructive feedback.

Conflicts of Interest: The authors declare no conflict of interest.

\section{Appendix A The Reflection Journal Prompts}

Reflection journal \#1

Please reflect on your learning experience during the past few weeks and briefly note down things related to:

- your teachers (e.g., Have you got to know them? Have you got any chance to directly communicate with them? Did they make their expectations clear? Do you like the teachers' course designs?)

- your classmates (e.g., Have you got to know them? Have you got any chance to interact with some of them? What are your impressions of your peers?)

- your learning (e.g., Are you clear about how each course works? Have you figured out how to manage your learning? What challenges have you come across up to now? Did you solve the problems? Are you planning to make any adjustments for the next few weeks?)

The above guiding questions are just for your reference. You don't need to answer all of them. It will be good to focus on things that stood out to you. Feel free to make any comments or note down any relevant examples or incidents. Please do not mention the course number/title or the name of any instructor or student in your reflection journal.

\section{Reflection journal \#2}

Please reflect on your learning experience during the past few weeks (since you completed your first reflection) and briefly note down things related to:

- your teachers (e.g., How well do you know the teachers now? Did you get any feedback from the teachers on your assignments or discussion posts? How do you like it? Did you find it easy to communicate with your teachers virtually?)

- your classmates (e.g., How well do you know your classmates now? Have you got any chance to work together with them? Have you got any feedback from them? How do you like it? What are your impressions of your peers now?)

- your learning (e.g., How did you manage your learning? How well were you engaged in the course content? Have you figured out how to solve some of the problems you came across at the beginning of the term? Have you come across any new challenges? How did you solve them? Did you find the help you need?)

The above guiding questions are just for your reference. You don't need to answer all of them. It will be good to focus on things that stood out to you. Feel free to make any comments or note down any relevant examples or incidents. Please do not mention the course number/title or the name of any instructor or student in your reflection journal.

Reflection journal \#3

Please reflect on your learning experience during the past few weeks (since you completed your second reflection) and briefly note down things related to:

- your teachers (e.g., How would you describe your impression of your teachers during the past few weeks? Did your teachers offer support to help with your assignments? Did you find it helpful? Did you find some instructors' support more effective than others? How?) 
- your classmates (e.g., How would you describe your relationship with your classmates during the past few weeks? Did you get to know more about your classmates? How? How did that help with your learning? Did you feel that your classmates have had a better understanding of you? How did you tell? How did that help with your learning?)

- $\quad$ your learning (e.g., How would you describe your learning during the past few weeks? Have you changed your view on the role of online discussions in your remote learning? How? Did you find the end-of-term exams or assignments challenging? Did you reach out for support? To whom? Was that helpful? Did you come across any new challenges during the past few weeks? Did you find the support you need to solve these problems?)

The above guiding questions are just for your reference. You don't need to answer all of them. It will be good to focus on things that stood out to you. Feel free to make any comments or note down any relevant examples or incidents. Please do not mention the course number/title or the name of any instructor or student in your reflection journal.

\section{References}

1. Buckner, E.; Zhang, Y.; Blanco, G.L. The impact of COVID-19 on international student enrolments in North America: Comparing Canada and the United States. High. Educ. Q. 2021, 1-15. [CrossRef]

2. EDUCAUSE Review. The Difference between Emergency Remote Teaching and Online Learning. Available online: https: / / er.educause.edu/articles/2020/3/the-difference-between-emergency-remote-teaching-and-online-learning (accessed on 5 December 2021).

3. Khotimah, K. Exploring online learning experiences during the COVID-19 pandemic. In IJCAH 2020; Atlantis Press: East Java, Indonesia, 2020.

4. Alawamleh, M.; Al-Twait, L.M.; Al-Saht, G.R. The effect of online learning on communication between instructors and students during covid-19 pandemic. Asian Educ. Dev. Stud. 2020. [CrossRef]

5. Gelles, L.A.; Lord, S.M.; Hoople, G.D.; Chen, D.A.; Mejia, J.A. Compassionate flexibility and self-discipline: Student adaptation to emergency remote teaching in an integrated engineering energy course during COVID-19. Educ. Sci. 2020, 10, 304. [CrossRef]

6. Kovačević, I.; Anđelković Labrović, J.; Petrović, N.; Kužet, I. Recognizing predictors of students' emergency remote online learning satisfaction during COVID-19. Educ. Sci. 2021, 11, 693. [CrossRef]

7. Makgahlela, M.; Mothiba, T.M.; Mokwena, J.P.; Mphekgwana, P. Measures to enhance student learning and well-being during the COVID-19 pandemic: Perspectives of students from a historically disadvantaged university. Educ. Sci. 2021, 11, 212. [CrossRef]

8. Poláková, P.; Klímová, B. The perception of Slovak students on distance online learning in the time of coronavirus-A preliminary study. Educ. Sci. 2021, 11, 81. [CrossRef]

9. Lambert, C.G.; Rennie, A.E. Experiences from covid-19 and emergency remote teaching for entrepreneurship education in Engineering Programmes. Educ. Sci. 2021, 11, 282. [CrossRef]

10. Limniou, M.; Varga-Atkins, T.; Hands, C.; Elshamaa, M. Learning, student digital capabilities and academic performance over the COVID-19 pandemic. Educ. Sci. 2021, 11, 361. [CrossRef]

11. Tsang, J.; So, M.; Chong, A.; Lam, B.; Chu, A. Higher education during the pandemic: The predictive factors of learning effectiveness in COVID-19 online learning. Educ. Sci. 2021, 11, 446. [CrossRef]

12. Garrison, D.R.; Anderson, T.; Archer, W. Critical inquiry in a text-based environment: Computer conferencing in higher education. Internet High. Educ. 2000, 2, 87-105. [CrossRef]

13. Castellanos-Reyes, D. 20 years of the Community of Inquiry framework. TechTrends Link. Res. Pract. Improv. Learn. 2020, 64, 557-560. [CrossRef]

14. Jan, S.; Vlachopoulos, P.; Parsell, M. Social network analysis and online learning in communities in higher education: A systematic literature review. Online Learn. 2019, 23, 249-265.

15. Richardson, J.C.; Maeda, Y.; Lv, J.; Caskurlu, S. Social presence in relation to students' satisfaction and learning in the online environment: A meta-analysis. Comput. Hum. Behav. 2017, 71, 402-417. [CrossRef]

16. Stenbom, S. A systematic review of the Community of Inquiry survey. Internet. High. Educ. 2018, 39, 22-32. [CrossRef]

17. Garrison, D.R. E-Learning in the 21st Century: A Framework for Research and Practice, 3rd ed.; Routledge: New York, NY, USA, 2017.

18. Anderson, T.; Rourke, L.; Garrison, D.R.; Archer, W. Assessing teaching presence in a computer conferencing context. J. Asynchronous Learn. Netw. 2001, 5, 1-17. [CrossRef]

19. Anagnostopoulos, D.; Basmadjian, K.G.; McCrory, R.S. The decentered teacher and the construction of social space in the virtual classroom. Teach. Coll. Rec. 2005, 107, 1699-1729. [CrossRef]

20. Arbaugh, J.B. An empirical verification of the community of inquiry framework. J. Asynchronous Learn. Netw. 2007, 11, 73-85. [CrossRef]

21. Arbaugh, J.B.; Hwang, A. Does “teaching presence" exist in online MBA courses? Internet. High. Educ. 2006, 9, 9-21. [CrossRef] 
22. Oriogun, P.K.; Ravenscroft, A.; Cook, J. Validating an approach to examining cognitive engagement in online groups. Am. J. Distance Educ. 2005, 19, 197-214. [CrossRef]

23. Tirado-Morueta, R.; Maraver-López, P.; Hernando-Gómez, Á.; Harris, V.W. Exploring social and cognitive presences in communities of inquiry to perform higher cognitive tasks. Internet. High. Educ. 2016, 31, 122-131. [CrossRef]

24. Shea, P.; Hayes, S.; Smith, S.U.; Vickers, J.; Bidjerano, T.; Pickett, A.; Gozza-Cohen, M.; Wilde, J.; Jian, S. Learning presence: Additional research on a new conceptual element within the Community of Inquiry (CoI) framework. Internet. High. Educ. 2012, 15, 89-95. [CrossRef]

25. Lam, J.Y.C. Autonomy presence in the extended community of inquiry. Int. J. Contin. Educ. Lifelong Learn. 2015, 8, 39-61.

26. Cleveland-Innes, M.; Campbell, P. Emotional presence, learning, and the online learning environment. Int. Rev. Res. Open. Distance Learn. 2012, 13, 269-292. [CrossRef]

27. Jiang, M.; Koo, K. Emotional presence in building an online learning community among non-traditional graduate students Online Learn. 2020, 24, 93-111. [CrossRef]

28. Majeski, R.A.; Stover, M.; Valais, T. The community of inquiry and emotional presence. Adult Learn. 2018, 29, 53-61. [CrossRef]

29. Phirangee, K.; Hewitt, J. Loving this dialogue!!!!: Expressing emotion through the strategic manipulation of limited non-verbal cues in online learning environments. In Emotion, Technology, and Learning; Tettegah, S.Y., McCreery, M.P., Eds.; Elsevier: San Diego, CA, USA, 2016; pp. 69-85.

30. Torres, I.; Evans, J. Emotion and online learning. In Proceedings of the Society for Information Technology \& Teacher Education International Conference, San Diego, CA, USA, 7 April 2020.

31. Zembylas, M. Adult learners' emotions in online learning. Distance Educ. 2008, 29, 71-87. [CrossRef]

32. Adedoyin, O.B.; Soykan, E. COVID-19 pandemic and online learning: The challenges and opportunities. Interact. Learn. Environ. 2020, 1-13. [CrossRef]

33. Bozkurt, A.; Sharma, R.C. Emergency remote teaching in a time of global crisis due to CoronaVirus pandemic. Asian J. Distance Educ. 2020, 15, i-vi.

34. Yates, A.; Starkey, L.; Egerton, B.; Flueggen, F. High school students' experience of online learning during COVID-19: The Influence of Technology and Pedagogy. Technol. Pedagog. Educ. 2020, 30, 59-73. [CrossRef]

35. Dhawan, S. Online learning: A panacea in the time of covid-19 crisis. J. Educ. Technol. Syst. 2020, 49, 5-22. [CrossRef]

36. Doll, K.; Ragan, M.; Calnin, G.; Mason, S.; House, K. Adapting and enduring: Lessons learned from international school educators during COVID-19. J. Res. Int. Educ. 2021, 20, 114-133. [CrossRef]

37. Mekone, Y.K ; Nneoma, N.C. The two sides of online learning post COVID-19: Perspectives of international students in China. Int. J. Res. Publ. 2021, 71, 44-57. [CrossRef]

38. Greenhow, C.; Lewin, C.; Staudt Willet, K.B. The educational response to COVID-19 across two countries: A critical examination of initial digital pedagogy adoption. Technol. Pedagog. Educ. 2020, 30, 7-25. [CrossRef]

39. Bu, F.; Steptoe, A.; Fancourt, D. Who is lonely in lockdown? Cross-cohort analyses of predictors of loneliness before and during the COVID-19 pandemic. Public Health 2020, 186, 31-34. [CrossRef] [PubMed]

40. Ezra, O.; Cohen, A.; Bronshtein, A.; Gabbay, H.; Baruth, O. Equity factors during the COVID-19 pandemic: Difficulties in emergency remote teaching (ERT) through online learning. Educ. Inf. Technol. 2021, 26, 7657-7681. [CrossRef] [PubMed]

41. Massachusetts Institute of Technology, MIT Teaching Systems Lab. Remote Learning Guidance from State Education Agencies during the COVID-19 Pandemic: A First Look. Available online: https:/ / osf.io/k6zxy/ (accessed on 30 December 2021).

42. PBS NewsHour. 'This Is Not Working'. Parents Juggling Jobs and Child Care under COVID-19 See No Good Solutions. Available online: https:/ / www.pbs.org/newshour/health/this-is-not-working-parents-juggling-jobs-and-child-care-under-covid-19 -see-no-good-solutions (accessed on 30 December 2021).

43. Brown, R.E. The process of community-building in distance learning classes. Internet. High. Educ. 2001, 5, 18-35. [CrossRef]

44. VanLeeuwen, C.A.; Veletsianos, G.; Belikov, O.; Johnson, N. Institutional perspectives on faculty development for digital education in Canada. Can. J. Learn. Technol. 2020, 46, 27944. [CrossRef] 